\title{
O DESAFIO DO CONCEITO DE PERFORMANCE NO CAMPO DA SUSTENTABILIDADE E DO DESIGN COMPUTACIONAL
}

\author{
THE CHALLENGE OF THE PERFORMANCE CONCEPT WITHIN \\ THE SUSTAINABILITY AND COMPUTATIONAL DESIGN FIELD
}

\author{
Marcio Nisenbaum', José Ripper Kós²
}

RESUMO: Este artigo discute o conceito de performance e sua apropriação nas áreas de pesquisa relacionadas à sustentabilidade e ao design computacional, enfocando os processos projetuais dos campos da arquitetura e do urbanismo. Recentemente, termos como "design orientado pela performance" ou "arquitetura orientada pela performance", sobretudo quando relacionados à sustentabilidade, têm figurado no vocabulário de autores e profissionais na busca por diretrizes de projeto baseadas em processos de simulação e uso sistemático de ferramentas digitais. Nesse contexto, a noção de performance tem sido compreendida principalmente como sinônimo de desempenho, alinhando-se a discursos contemporâneos de eficiência e otimização - considera-se, nessas circunstâncias, que um edifício ou um recorte urbano "performa" quando atende a determinados critérios objetivos de avaliação de sustentabilidade, reduzida a parâmetros matemáticos. Pretende-se neste artigo justamente ampliar essa visão a partir de novas interpretações teóricas, recorrendo à investigação etimológica, pesquisa histórica e revisão de literatura, com base em autores de diferentes áreas e no estudo de caso da competição acadêmica de casas solares, o Solar Decathlon. Espera-se que essa análise inicial contribua para a emergência de novas formas de entendimento do conceito de performance, relativizando a noção de "corpo" que "performa" em diferentes vieses, potencializando assim sua apropriação e utilização no campo da sustentabilidade e do design computacional.

PALAVRAS-CHAVE: Design Orientado pela Performance; Design Computacional; Sustentabilidade; Solar Decathlon.

\begin{abstract}
This paper discusses the notion of performance and its appropriation within the research fields related to sustainability and computational design, focusing on the design processes of the architectural and urban fields. Recently, terms such as "performance oriented design" or "performance driven architecture", especially when related to sustainability, have been used by many authors and professionals as an attempt to engender project guidelines based on simulation processes and systematic use of digital tools. In this context, the notion of performance has basically been understood as the way in which an action is fulfilled, agreeing to contemporary discourses of efficiency and optimization - in this circumstance it is considered that a building or urban area "performs" if it fulfills certain objective sustainability evaluation criteria, reduced to mathematical parameters. This paper intends to broaden this understanding by exploring new theoretical interpretations, referring to etymological investigation, historical research, and literature review, based on authors from different areas and on the case study of the solar houses academic competition, Solar Decathlon. This initial analysis is expected to contribute to the emergence of new forms of interpretation of the performance concept, relativizing the notion of the "body" that "performs" in different manners, thus enhancing its appropriation and use within the fields of sustainability and computational design.
\end{abstract}

KEYWORDS: Performance-oriented-design; Computational Design; Sustainability; Solar Decathlon.

\section{How to cite this article:}

NISENBAUM, M.; KÓS, J. R. O desafio do conceito de performance no campo da sustentabilidade e do design computacional. Gestão e Tecnologia de Projetos, São Carlos, v. 12, n. 3, p. 77-92 2017. http://dx.doi.org/10.11606/gtp. v12i3.134314
Fonte de financiamento: Conselho Nacional de Desenvolvimento Científico e Tecnológico (CNPq) Coordenação de Aperfeiçoamento de Pessoal de Nível Superior (Capes)

Conflito de interesse: Declaram não haver Submetido em: 10/07/2017 Aceito em: 25/08/2017 


\section{INTRODUÇÃO}

O uso do termo performance como um conceito norteador de processos projetuais e formas de avaliação tem se tornado cada vez mais recorrente no campo da arquitetura e do urbanismo. Em especial, na área de pesquisa do design computacional e da sustentabilidade, o termo tem inspirado produções teóricas e práticas que exploram alguns de seus possíveis significados. Percebemos tal apropriação nas pautas das últimas edições de congressos de Gráfica Digital (como os SIGraDI, eCAADe, Acadia, Caadria, Ascaad), em publicações de revistas, como a Architectural Design, e nas práticas projetuais contemporâneas envolvendo o uso da computação. Em plataformas virtuais de artigos, como o CumInCAD, por exemplo, uma busca pela palavra "performance" encontra 1164 resultados, num universo de 12372 artigos.

Nesse contexto, o uso do termo é feito muitas vezes na tentativa de alinhar o discurso do design digital com o da sustentabilidade e da resiliência. Tem predominado a interpretação de performance como desempenho, um "termômetro" que avalia se um edifício ou uma cidade atinge determinada "meta". Contudo, a falta de reflexão e questionamento acerca do termo em si limita seus possíveis desdobramentos teóricos, reduzindo o potencial do conceito. Sua apropriação no campo de estudo e experimentação dos meios digitais parece, a princípio, um tanto reduzida a aspectos quantitativos e critérios objetivos.

Assim, seria importante investigar de maneira mais aprofundada o termo em questão, entender sua gênese, suas diferentes interpretações e desdobramentos, na tentativa de extrair possibilidades enriquecedoras. Cabe ressaltar que não se pretende aqui articular uma noção finalizada de performance - até porque isso exigiria um aprofundamento teórico em diferentes áreas de pesquisa -, mas apenas apontar alguns possíveis caminhos, enfocando interesses do campo do design computacional, assim como fazer referência a algumas obras e autores relevantes.

\section{O CONCEITO}

Uma investigação do termo performance nos leva a transitar por campos de conhecimento diversos e formas de interpretação variadas, que tornam complexa uma definição objetiva. A própria referência ao termo já não é simples: seria performance um conceito, um tema, um campo de estudo ou uma disciplina?

\section{Em busca de definições}

Numa primeira tentativa de conceituação da palavra, pode-se recorrer à etimologia: performance advém do latim, formada a partir do prefixo per mais formáre. Segundo o dicionário Aurélio, per pode assumir o significado de movimento através, proximidade, intensidade ou totalidade, como em percorrer, perdurar, perpassar. Já formáre se refere a formar, dar forma, estabelecer, constituir, entendendo-se forma como os "limites exteriores da matéria de que é constituído um corpo, e que confere a este um feitio, uma configuração, um aspecto particular” (FERREIRA, 2004).

Duarte e Noronha (2011, p. 2) destacam que performance "pode designar, entre outras coisas, a aparência física ou desempenho do corpo, ou ainda, um método a partir do qual se origina um corpo.” Tal definição, assim como as encontradas no dicionário, dá margem a muitas intepretações, o que explica o fato de o termo ser apropriado por diferentes áreas de pesquisa e assumir significados diversos ao longo da história.

O uso e a significação do termo performance como entendemos hoje parece ter se originado nas décadas de 1940 e 1950, consolidando-se 
através do movimento intelectual chamado Performative Turn (Virada Performática). Mais do que um movimento, a Virada Performática teria sido um conjunto de teorias imbricadas, com fronteiras voláteis e diversas possibilidades semânticas. Como sugerem Duarte e Noronha (2011, p. 2), “o termo performance é um território de várias interfaces, de trajetos múltiplos, e por sua natureza multidisciplinar, é uma arte de fronteira.” Fazem parte da "rede teórica" que lidou com o termo alguns autores como: Kenneth Duva Burke (1897-1993), americano, filósofo e teórico da literatura; Victor Witter Turner (1920-1983), antropólogo inglês; Erving Goffman (1922-1982), sociólogo américo-canadense; John L. Austin (1911-1960), filósofo e linguista britânico; entre outros. Os perfis distintos dos "atores" que participaram desse momento fizeram com que o conceito ressoasse em diversos campos de conhecimento, como nas artes, na música, na literatura e no teatro. A contribuição desses autores nem sempre é clara e explícita, mas de alguma forma colaboraram para a constituição de um quadro teórico que nos dá alguns indícios dos significados do termo em questão até os dias de hoje.

Turner, por exemplo, desenvolve a ideia de performance a partir da obra de Van Gennep, Ritos de passagem, articulando a ideia de ritual como processo (HENSEL, 2013). Para o autor, os rituais repetidos podem gerar novos significados e se opor a sistemas de representação, o que caracterizaria um sistema performático. Em seus últimos estudos, baseados em um trabalho de campo que realizou na África por meio de observação dos rituais dos povos Ndembu, Turner buscava lançar bases para uma vertente antropológica denominada Antropologia da performance.

A obra de Turner, por sua vez, influenciou o diretor teatral e antropólogo Richard Schechner, uma referência no estudo sobre performance no campo do Teatro, tendo escrito importantes obras, como Between antropology and theater (1985) e Performance theory (1988). Schechner buscou ampliar a noção de performance à luz de sua formação. Ao relacionar a noção de rito com teatro, o autor procurou compreender o processo de transformação que ocorre durante uma encenação, tanto do “corpo" do ator quanto da própria audiência.

Num viés semelhante, alguns autores buscam relacionar o conceito de performance com o de "agência". Segundo Hensel (2013), na Filosofia e na Sociologia, agência se refere à capacidade de uma pessoa ou entidade de "agir" ou "atuar" em determinado milieu, contexto. Essa interpretação estendeu a utilização do conceito de performance a áreas como as ciências naturais e tecnológicas. Segundo Pickering (1995 apud HENSEL, 2013, cap. 1, tradução nossa):

Em uma concepção mais ampla de cultura científica... - uma que transcenda ciência-como-conhecimento para incluir dimensões materiais, sociais e temporais - é possível imaginar ciência além da representação [...]. Pode-se entender que o mundo não é constituído, num primeiro momento, com fatos e observações, mas com agência.

Outra leitura relevante do conceito de performance é a da filósofa Judith Butler, que se apropriou do termo para teorizar questões de gênero e identidade. Em uma de suas obras mais influentes, Gender trouble: feminism and the subversion of identity, publicada em 2006, a autora desenvolve a ideia do gênero não como uma condição ontológica, mas como algo gerado de forma performática. Em sua visão, a identidade poderia ser construída pela repetição de gestos, ações e comportamentos, e não por uma pré-condição genética. Tal abordagem se assemelha à ideia de ritual desenvolvida por Turner e Schechner.

\section{O conceito de performance no campo da arquitetura}

A noção de performance no campo da arquitetura e em outras áreas do conhecimento se abriu a diversas interpretações. Desde a busca por 
uma arquitetura performática, em que o próprio objeto arquitetônico "atuaria" num determinado contexto, até a noção de arquitetura como evento, um "palco" de acontecimentos, o termo foi utilizado de diferentes maneiras. Para Duarte e Noronha (2011), o entrelaçamento das diferentes perspectivas de interpretação se articula por meio da noção da performance como processo, ação, desempenho através de um corpo, contexto e tempo. Essa noção corporal pode ser relativizada de acordo com diferentes referenciais: o "corpo" como presença física, como o próprio objeto edificado, ou ainda o “corpo" do autor (arquiteto) e historiador que analisa a obra.

A primeira interpretação remete, a princípio, a questões de leituras espaciais à luz do conceito de "acontecimento". Nesse sentido, podese evocar a obra de Tschumi, que sugere uma aproximação da noção de performance à ideia de evento:

Não existe arquitetura sem programa, sem ação, sem evento [...] arquitetura nunca é autônoma, nunca é pura forma [...] o objetivo é reinscrever o movimento dos corpos no espaço, junto com as ações e eventos que acontecem no âmbito social e político da arquitetura. (TSCHUMI, 1994, p. 3-4, tradução nossa)

Nessa mesma linha, seria interessante investigar os já citados estudos de Judith Butler sobre gênero para entender como a forma arquitetônica e o espaço podem ser subvertidos através do uso repetitivo e, dessa forma, por meio de performance. Para a autora, o acúmulo de múltiplas práticas pode gerar novas percepções e significados em estruturas pré-condicionadas, como o corpo humano. Inspirado em sua obra, Neil Leach (2006), no texto "Drag Spaces", faz uma analogia do corpo travestido com o espaço subvertido:

a noção de performance de gênero pode ser importada para o campo do estudo de apropriações espaciais: se identidade pode ser construída através da performance, o espaço no qual ela ocorre pode ser visto como um palco. Após uma repetição de performances esse palco não é mais neutro. Ele será imbuído de associações de atividades que ocorreram. (LEACH, 2006, p. 6, tradução nossa)

A segunda forma de interpretação à luz da noção de corpo sugerida por Duarte e Noronha procura entender o próprio objeto arquitetônico como o "corpo" em questão. Nesses termos, cabe recorrer à obra de David Leatherbarrow (2009, 2013), que no livro Architecture oriented otherwise e em outras obras, se dedica a novas interpretações do conceito de performance. Para o autor:

Quando um edifício é entendido como o locus da performance (e não soluções funcionais), ele pode ser visto como uma preparação e uma resposta; um conjunto de condições que não só antecipam ocorrências mas reagem a elas, através da antecipação no primeiro caso e participação no segundo. (LEATHERBARROW, 2013, prefácio, tradução nossa)

Explorando a ideia renascentista de contraposto - uma posição equilibrada entre partes do corpo tensionadas e relaxadas - Leatherbarrow sugere que um objeto arquitetônico pode ser visto como um corpo em ação no tempo, "atuando" e se adaptando a solicitações não previstas. Nesse sentido, o "corpo" do edificado se mistura com o do autor, do planejado, num jogo de tensões. Essa noção se aproxima à de Noronha e Duarte (2011, p. 4): "a obra de arquitetura incorpora as vicissitudes do trajeto, os acasos das mudanças de rumo [...], o atravessamento de multiplicidades na qual o acidente configura em uma realidade existencial”. 


\section{PERFORMANCE NO CAMPO DO DESIGN COMPUTACIONAL}

Antes de entender como o termo performance foi apropriado, é importante apresentar algumas definições para a área de pesquisa do design computacional. Pode-se considerar que esse campo investigativo começou a se desenvolver na década de 1960, a partir de debates sobre métodos em projetos, e buscava entender desde o nascimento da computação como seria sua incorporação aos meios criativos. Segundo Celani (2008, p. 13), o campo do design computacional busca desenvolver "por um lado, uma teoria computacional do processo de projeto apoiada nas ciências cognitivas, e por outro, métodos e aplicações que permitam o desenvolvimento de projetos com o uso de meios computacionais." Ainda segundo a autora, fazem parte desse campo de teorias e metodologias a "gramática da forma", os "autômatos celulares”, a "computação evolucionária” (algoritmos genéticos) e as "transformações topológicas" (CELANI, 2008, p. 5).

No que se refere ao design methods, constata-se que as primeiras discussões já colocavam em debate um olhar dicotômico, confrontando arte e ciência, como verificado na famosa Conferência em Métodos Sistêmicos e Intuitivos na Engenharia, Desenho Industrial, Arquitetura e Comunicação, realizada em Londres no ano de 1962, organizada por Christopher Jones e Bruce Archer (VARDOULI, 2014, p. 84). Tal conferência, assim como outras que a sucederam, buscava em áreas além do design e da arquitetura inspirações para metodologias de projeto de ordem mais "científica". Autor de referência desse contexto, Christopher Alexander, por exemplo, propunha o pensamento lógico e a aplicação de métodos sistêmicos no processo de design, como verificado em sua obra seminal Notes on synthesis of the form. Contudo, autores como Theodora Vardouli (2014) apontam que naquele contexto alguns pensadores já se posicionavam de forma crítica, confrontando, a partir de argumentos filosóficos, psicológicos e éticos, a lógica "behaviorista" proposta por outros estudiosos à época. Cabe destacar uma das primeiras aparições do termo performance design, expressão que foi capa do jornal norte-americano Progressive Architecture, de 1967. Na publicação, o conceito de performance alinhava-se ao viés sistêmico defendido por autores que cada vez mais especulavam sobre os impactos da tecnologia e da computação nos processos de projeto.

Nas décadas de 1980 e 1990, as experimentações computacionais culminaram na proliferação dos "blobs", formas complexas que dependiam da tecnologia computacional para existirem num meio digital, mesmo que não materializadas. Nesse contexto, emergiram novas teorias, como a "arquitetura líquida" de Marcos Novak e a "transarquitetura", de Greg Lynn. Novak já propunha discussões acerca de sistemas generativos e o entendimento do arquiteto como um compositor digital, que deveria dominar a linguagem computacional para organizar as relações espaciais. Entretanto, o autor compreendia que o "design assistido pelo computador" (CAD) não deveria se afastar das artes, pelo contrário, deveria buscar influências em campos como música, literatura, pintura e poesia, o que se verificava em suas próprias experimentações (NOVAK, 1988).

Nesse período também foi notável a evolução computacional no que se referia aos processos de renderização e produção de imagens e animações fotorrealistas. A proliferação de novos softwares, assim como a apropriação de programas de outras áreas para gerar efeitos visuais complexos, estimulou a substituição de métodos de representação manuais por software de modelagem geométrica e procedural, com interfaces cada vez mais amigáveis. Já nas últimas décadas, os estudos envolvendo computação começaram a apontar novos caminhos, se esquivando do formalismo complexo e buscando alinhar suas descobertas com os debates contemporâneos, principalmente no âmbito da sustentabilidade. As novas formas de uso do digital passaram assim a incluir métodos de otimização estrutural, redução do consumo energético, maximização do conforto 
térmico e acústico etc., possibilitadas pela alta capacidade de simulação computacional. Tais manifestações buscam um "novo lugar ao sol" para as arquiteturas digitais, sugerindo o papel da computação como parte do processo projetual e não apenas uma ferramenta representacional.

As novas ferramentas digitais, como o Building Information Modeling (BIM), e as possibilidades de design paramétrico e algorítmico contribuíram para que essa nova perspectiva emergisse. Nesse contexto, o termo performance ganhou novos significados. O desenvolvimento tecnológico permitiu processos mais precisos de avaliação, através de softwares de simulação. Testes de desempenho passaram a ser feitos em tempo real, na busca de resultados otimizados e "selo" sustentável. Soma-se a esse potencial de análise as possibilidades generativas, em que o próprio computador testa diferentes cenários e escolhe os mais eficientes, por meio de algoritmos evolutivos, por exemplo. Nesse quadro, o entendimento de performance compreende não apenas a análise do resultado final, mas as contingências de manipulação de geometrias complexas pelo usuário, configurando possibilidades de formas adaptativas e resilientes a partir da emergência de interações materiais e/ou ambientais por meio de parametrização. Para Aish e Woodbury (2005, p. 1, tradução nossa): "a parametrização aumenta a complexidade do design e de sua interface na medida que designers precisam modelar não apenas o artefato idealizado, mas também sua estrutura conceitual que permita a manipulação de variações”.

No campo das representações, tem sido recorrente o uso de gradientes de cor para demonstrar a eficiência e ineficiência do objeto edificado em relação aos critérios analisados - sejam de ordem estrutural, térmica, lumínica, acústica etc. (Figura 1). Tais imagens explicitam forças e tensões que representações tradicionais não reproduzem, dando margem a interpretações de tipos de performance de edifícios e de cidades.

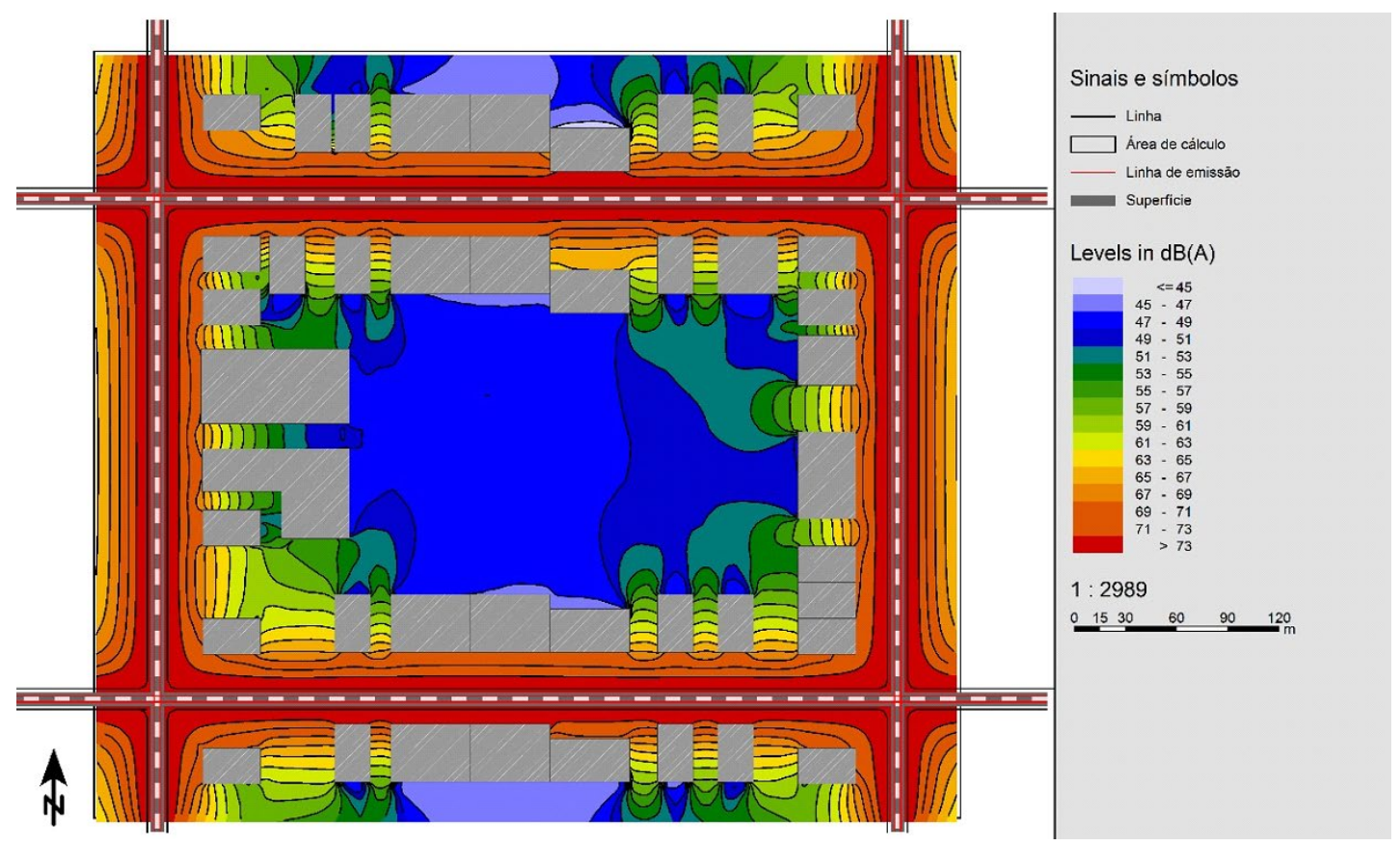

Figura 1: Simulação de interações acústicas numa quadra genérica, usando o software Soundplan

Fonte: Elaborada pelos autores
Nesse novo panorama, alguns autores passaram a se debruçar sobre a questão da performance como um novo paradigma de design. Termos como performance-oriented design (ou performance-oriented architecture) ou, ainda, performance-driven-design passaram a figurar nas discussões teóricas no campo do design computacional. Destacam-se nesse contexto as produções teóricas de Michael Hensel (2013), Branko Kolarevic e Ali Malkawi 
(2010), Rivka Oxman (2008, 2012), entre outros. Tais autores exaltam as novas possibilidades do "performance design", mas também propõem abordagens inéditas que buscam compreender performance além da "otimização".

Oxman, por exemplo, analisa o processo de design baseado em performance destacando a nova postura que o profissional deve assumir no processo criativo. "É o potencial de integração de processos de simulação avaliativa com geração de formas digitais e transformações formais em modelos que definem o processo chamado performative design" (OXMAN, 2008, p. 3, tradução nossa). Para a autora, o designer desse novo contexto passa a ser um mediador de interações morfológicas baseadas em critérios de otimização e adaptação, controlando um processo conhecido como formfinding. Contudo, a autora também afirma que a noção de performance deve ser entendida para além da visão exclusivamente técnica:

Performance aqui é definida como a habilidade de agir diretamente nas propriedades físicas do design específico. Além das propriedades quantitativas, as classes das propriedades podem eventualmente ser ampliadas para incluir aspectos qualitativos como fatores espaciais em simulações técnicas. (OXMAN, 2012, p. 24, tradução nossa)

Já Hensel (2013) explora performance a partir do processo de interação (espacial e material) da arquitetura com a morfologia urbana e o ecossistema local. Retomando a questão da "agência" como elemento fundamental do entendimento de performance, ele aponta quatro fatores que interagem e norteiam o performance-oriented-design: “(a) comunidades locais - fatores bióticos e interações (b) o meio físico local - fatores abióticos (c) organização espacial e (d) organização material” (HENSEL, 2013, cap. 5). O autor também busca aproximar performance à noção de evento, que se verifica na relação da arquitetura e seus usos, como nas apropriações espaciais não planejadas, por exemplo. Para isso, ele se utiliza de conceitos trabalhados por Tschumi, contrapondo a noção de ressignificação espacial pela movimentação corporal à dicotomia forma e função.

Nesse mesmoviés, Kolarevice Malkawi(2010,p.205) destacamque “emuma arquitetura performática o espaço se desdobra em formas indeterminadas, em contraste à rigidez do predeterminado, ações programadas, eventos e efeitos”. Ele alerta para o fato de o conceito de performance ultrapassar as dimensões estéticas e funcionais. Assim, pode-se falar em performance financeira, cultural, espacial e social, além da performance de aspectos técnicos mais recorrentes (estrutural, térmico etc.). Uma de suas grandes contribuições para o campo de estudos é a compreensão de performance como um processo, o que demanda uma revisão do entendimento de “corpo edificado" enquanto "corpo estático”: "É necessária uma mudança de aspectos cenográficos [de edifícios] à imaginação pragmática de como um edifício funciona, o que faz, e quais ações, eventos e efeitos promove no tempo” (KOLAREVIC; MALKAWI, 2010, p. 212, tradução nossa).

\section{A PERFORMANCE E A SUSTENTABILIDADE}

O crescimento de catástrofes ambientais e da conscientização da população posicionou o tema da sustentabilidade em um relevante patamar do debate arquitetônico. As comunidades primitivas frequentemente buscaram adaptar as edificações às condições climáticas locais, especialmente em circunstâncias extremas. Em muitos casos, o conforto interno proporcionado pelas moradias era uma questão de sobrevivência para essas comunidades. O desenvolvimento das tecnologias relacionadas às edificações proporcionou novas formas de controle das interações entre os espaços internos das edificações e o ambiente externo. Padrões de conforto, especialmente ligados 
a temperatura, iluminação, acústica, entre outros elementos, passaram a ser os principais objetivos das pesquisas dessas novas tecnologias. As condições de conforto dos usuários no interior das edificações tornaram-se muito semelhantes, mesmo que em condições externas muito diferentes. Essas condições eram proporcionadas por dispositivos que, frequentemente, demandavam grande quantidade de energia.

O debate acerca da sustentabilidade no ambiente construído cresceu associado em grande parte a situações de crise energética, geradas por diversos fatores, especialmente tensões políticas, mercado internacional e preocupações ambientais sobre os impactos da geração de energia. Da mesma forma, o impacto ambiental relacionado aos edifícios está fortemente vinculado ao seu consumo energético. Nesse contexto, surgem diversas formas de certificação que buscam meios de garantir a redução do impacto ambiental ou da eficiência energética das edificações. Essas certificações definem critérios verificados nos projetos e, algumas vezes, na edificação construída. Vários desses critérios são verificados através da demonstração da performance da edificação, utilizando-se programas de simulação computacional, ferramentas que ganharam novo impulso entre os projetistas para verificar a performance dos seus projetos, interferindo também no processo de projeto, em ações com vários níveis de interação. A limitação dessas ferramentas para reproduzir com precisão as condições do ambiente construído é uma questão crítica, especialmente para as certificações que determinam parâmetros de performance a serem obtidos e, muitas vezes, classificados em progressivos níveis ou categorias de certificação.

Diversas edificações com certificação apresentam um desempenho muito aquém daquele "prometido" nos processos de simulação (LI; HONG; YAN, 2014; NEWSHAM; MANCINI; BIRT, 2009). Isso se deve a aspectos não simulados que influenciaram a performance de forma mais significativa que o esperado, mas também ao modo como os dados foram manipulados por um crescente grupo de profissionais com expertise nessas ferramentas de simulação e credenciados pelas diversas agências de certificação. Para esse grupo, um resultado favorável comprovado pelas ferramentas é mais importante do que uma verificação realista das imprecisões nelas inseridas, as quais impactam a previsão da performance e sua averiguação durante o uso da edificação construída.

Pelas razões expostas, diversos autores desafiam as formas como a questão da sustentabilidade é apropriada, especialmente pela indústria. Uma das constantes nessas considerações é a necessidade de equipes transdisciplinares, trabalhando colaborativamente desde as fases iniciais do projeto. Esses fatores começam a ser avaliados com maior cuidado em alguns programas de certificação que possuem uma estrutura mais simplificada, mas ao mesmo tempo mais holística e efetiva. Uma questão importante que começa a ser incorporada ao debate, por exemplo, é que os edifícios não são certificados apenas pelo seu potencial de performance comprovado através de simulações, as quais se mostram frequentemente muito otimistas, quando comparadas com o edifício construído. Certificações como o Living Building Challenge (IMAGINE..., 2017) promovem uma nova forma de medição da performance. Para obtê-lo, os projetos devem "oferecer mais do que eles usam, criando um impacto positivo nos sistemas humano e natural que interagem com eles". Além disso, a certificação "exige uma performance real, em vez da antecipada, demonstrada ao longo de um monitoramento de doze meses consecutivos".

\section{O desafio da performance}

Burry et al. (2013, p. 18) apresentaram uma declaração desafiadora:

Em comparação com a arquitetura, a performance é mais transparente em um esporte de alto desempenho, como em competições de barcos a vela, onde é evidente que "velocidade é bom". 
Nos barcos de regatas, o objetivo principal é buscar a melhor performance possível. No caso de edificações, em grande parte das vezes a certificação com um bom ranking é mais importante para a divulgação do que uma boa performance do edifício construído. Para os proprietários, projetistas e responsáveis pela construção e venda das edificações, os ganhos de marketing são geralmente mais importantes que as economias de energia ou a redução do impacto ambiental. Quando a simulação da performance é mais valorizada do que a performance propriamente dita, evidencia-se uma dissociação do edifício como locus da performance sugerido no conceito de Leatherbarrow. A virtualização do corpo em ação no tempo substitui e praticamente desconsidera sua "atuação" e "adaptação" às solicitações externas, especialmente do meio ambiente. Ela reforça ainda posições críticas em relação à forma como a questão da sustentabilidade é incorporada à arquitetura. Alberto PérezGómez (2016, p. ii), por exemplo, identificou "as limitações radicais de um discurso sobre sustentabilidade que trata esse problema como uma mera questão tecnológica redutível a parâmetros matemáticos”.

Retomando as contribuições dos barcos a vela, destaca-se uma importante inovação ocorrida nos anos 1980 em competições de alta performance. Na regata internacional mais tradicional, a America's Cup, grande quantidade de recursos é destinada para pesquisas. Na época, teve início o uso de simulações em tempo real que avaliavam as condições ambientais e calculavam a performance do barco diante delas. Essa performance calculada passava a constituir um parâmetro a ser alcançado pela tripulação; definia um objetivo. A tripulação estabelecia então ajustes para se aproximar daquela velocidade, em última análise, a performance ideal. Ajustes eram necessários especialmente quando a diferença entre a velocidade ideal e a velocidade obtida se mostrava muito grande.

Ao longo da década de 1980, a America's Cup foi disputada nos famosos barcos 'Doze Metros', e foram feitos avanços significativos na construção do casco, no tecido e painéis das velas, e nos instrumentos de navegação. Mas, talvez mais do que as outras inovações, os instrumentos de navegação começaram a mudar a forma como os barcos eram navegados. As informações sobre os ângulos do vento e a velocidade foram melhores do que nunca, mas ser capaz de fazer cálculos que poderiam indicar o quão eficientemente o barco estava sendo navegado era o que estava mudando o jogo para os melhores velejadores do mundo. (TWELVE..., 2013)

Os instrumentos de navegação realizavam complexos cálculos e os exibiam em tempo real para a tripulação, permitindo avaliar o desempenho em relação ao potencial de velocidade do barco. Um dos velejadores de maior reconhecimento até hoje, o norte-americano Dennis Conner, reconhece o papel da precisão desses instrumentos para seu sucesso nas regatas naquele período (WHAT..., 2013). É importante destacar que a qualidade dos velejadores continua sendo uma das questões mais relevantes para o sucesso dos barcos nas regatas. O conhecimento dos fenômenos naturais e da forma como podem ser aproveitados no desempenho dos barcos é fundamental e tende a ser aprimorado pelos que melhor conseguem estabelecer uma conexão entre corpo, vento e mar. A ideia de corpo em ação no tempo se faz evidente na relação, obtida durante as regatas, entre a informação de cálculos computacionais e o fenômeno vivenciado pelos velejadores em direto contato com os ciclos da natureza.

O premiado arquiteto australiano Glenn Murcutt teve seu trabalho reconhecido especialmente pela valorização do meio ambiente e pela forma como resgata as tecnologias tradicionais, especialmente das comunidades primitivas (DREW, 1985). Ele também destaca a influência da experiência como velejador nos seus projetos de edificação, que retomam conceitos encontrados em moradias primitivas. 
E você ajusta esta casa, e a maioria dos meus edifícios, como você navega um barco a vela. Você tem que ajustá-la para que possa compreender como tirar o melhor proveito do clima sem precisar um ar-condicionado. (MURCUTT, 2008)

\section{A experiência do Solar Decathlon}

Competições acadêmicas, embora pouco frequentes, apresentam uma oportunidade instigante para o debate sobre performance na arquitetura. Nesse sentido, a competição mais relevante, o Solar Decathlon, avalia casas solares e estimula projetos transdisciplinares, elaborados de forma colaborativa. Um dos principais objetivos do Solar Decathlon é a difusão do uso de energia solar em residências, assim como a divulgação dessa alternativa energética para que o público em geral a adote.

Cerca de vinte equipes representando universidades de todo o mundo devem projetar, construir e habitar a casa mais eficiente, sustentável e inovadora que funcione exclusivamente com energia solar (térmica e fotovoltaica). As equipes, constituídas principalmente por alunos, devem cumprir dez provas que testam as inovações da casa, sua capacidade de geração e eficiência energética, o conforto, a qualidade espacial e construtiva, a viabilidade de implementação e um desenho que integre todos os sistemas.

As casas são projetadas a partir de várias simulações de performance, enviadas para os organizadores durante o processo de desenvolvimento da proposta. Após essa etapa, as casas construídas e testadas no campus de cada universidade ou grupos de universidades são transportadas para o local da competição. Lá, são montadas lado a lado, durante uma semana, permanecendo em exposição por dez dias, quando são abertas à visitação do público e para realização das provas.

As simulações são elaboradas para todo o ano e testadas ao longo das provas, as quais se dividem em dois grupos. Um deles, com critérios subjetivos, avalia a proposta como um todo, através de diferentes grupos de jurados com acesso às simulações de performance feitas durante a etapa do projeto. As demais provas, do segundo grupo, são baseadas em diferentes medições realizadas durante a competição. Nessas provas cada equipe desempenha atividades que simulam o uso regular de uma residência enquanto a performance desta é monitorada e disponibilizada em tempo real para todas as equipes e para o público em geral.

De modo crescente, o caráter educativo, tanto para estudantes e pesquisadores quanto para o público, tornou-se uma das principais preocupações do evento. Assim, a performance das casas assume uma posição de destaque e comprovação das tecnologias pesquisadas e construídas pelos estudantes e expostas ao público. Os universitários envolvidos na competição podem avaliar o resultado das tecnologias em diferentes condições e o controle da performance de suas casas, comparadas com as das demais equipes, em tempo real. A disponibilização dos dados permite que ajustes sejam feitos para melhorar a performance avaliada no contexto das outras casas. Embora as simulações computacionais realizadas nas etapas de projeto sejam consideradas na avaliação das casas, a performance continuamente monitorada, em cada uma das edificações, é priorizada, sendo o principal diferencial das provas. A disponibilização desses dados e os ajustes realizados pelos estudantes proporcionam uma conexão com o corpo, banalizada pelas simulações geralmente otimistas utilizadas para atender programas de certificação.

A primeira edição do Solar Decathlon aconteceu em Washington, em 2002, e foi idealizada por Richard King, do Departamento de Energia norteamericano. Em outubro de 2017, a cidade estadunidense de Denver, sediou a $13^{\mathrm{a}}$ edição da competição, já realizada em diversas cidades do planeta, 
sempre sob supervisão do seu idealizador (U.S. DEPARTMENT OF ENERGY, 2017). Em 2012, pela primeira vez uma equipe latino-americana, o Team Brasil, participou do evento, que na ocasião se deu em Madri, Espanha. Em 2018, Cali sediará a segunda edição da competição na América Latina, que possui um caráter mais inclusivo, direcionado para moradias de interesse social e com maior limitação de custos.

Mesmo as equipes que participam do evento questionam o caráter sustentável de uma competição que transporta protótipos de residências, muitas vezes entre diferentes continentes, para participar do evento. Entretanto, é essa oportunidade de montar protótipos lado a lado que aproxima todos os estudantes e transforma a competição em um sucesso de público e de estratégia de ensino. O período de montagem das casas, que dura mais de uma semana e requer árduo trabalho, é a primeira forma de aproximar os estudantes de diferentes universidades e países que fazem parte da competição. Os universitários passam cerca de dois anos trabalhando nesse empreendimento, assumindo responsabilidades que não são geralmente atribuídas a eles no processo de aprendizagem usual nas universidades. Nesse período, estudantes de diferentes áreas do conhecimento participam de um processo colaborativo, nem sempre bemsucedido, para criar, projetar, justificar, viabilizar, construir e transportar até o local da competição um protótipo de grande complexidade. A relação que os estudantes possuem com suas casas não é mais de criação de um conjunto de tecnologias capaz de cumprir as provas da competição. A relação é muito mais ampla, capaz de unir todas as equipes e possibilitar uma troca de experiências praticamente impossível nos métodos tradicionais de ensino.

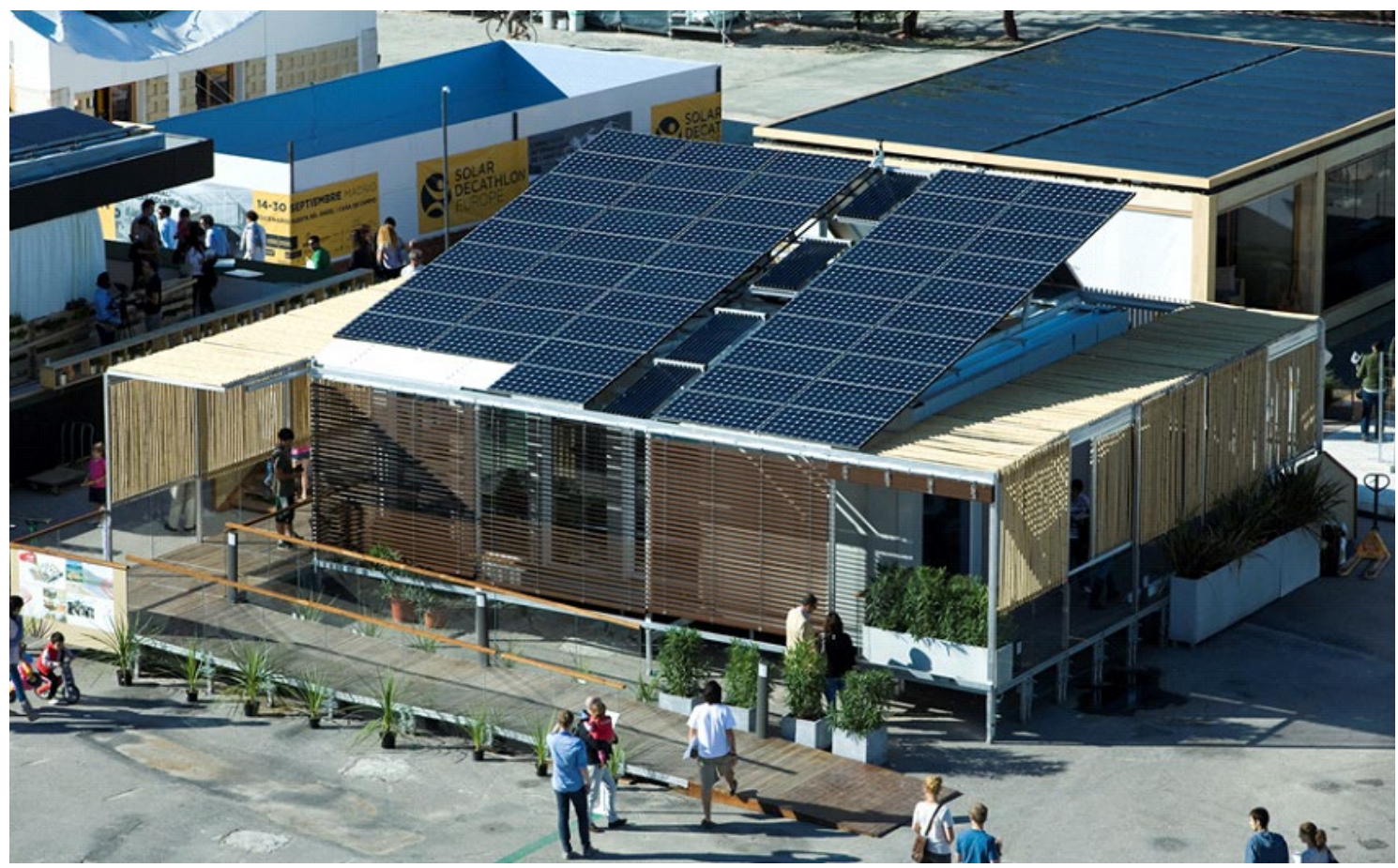

As provas são criadas para incentivar a colaboração entre diferentes áreas e avaliar o sucesso da equipe no empreendimento. Algumas examinam questões amplas, como arquitetura, engenharia e sustentabilidade, e outras, mais específicas, verificam o desempenho das casas enquanto os estudantes simulam o uso delas em condições normais. A competição europeia de 2012 incluiu um item na prova que mede a temperatura das casas. Nessa prova, as equipes ganham pontuação máxima no período em que garantem a temperatura interna entre 23 e $25^{\circ} \mathrm{C}$ e ganham pontos reduzidos quando
Figura 2: A casa brasileira em Madri, 2012

Fonte: Solar Decathlon Europe 2012 / I+D+Art 
conseguem manter as temperaturas mais próximas desse intervalo. No Solar Decathlon Europe 2012, realizado em Madri (Figura 2), as equipes foram monitoradas por dez dias consecutivos. Durante 56 horas, não puderam recorrer a métodos ativos de condicionamento do ar, apenas a sistemas considerados semipassivos, com bombas ou ventiladores. Nessa edição, houve especial atenção das equipes para o desenvolvimento de métodos passivos para garantir o conforto de suas casas, estratégias que já eram avaliadas nas edições anteriores do evento, mas pela primeira vez foram diretamente monitoradas (RODRIGUEZ-UBINAS et al., 2014). As equipes criaram grande diversidade de técnicas, que exigiam, muitas vezes, uma interação mais próxima dos estudantes com as condições apresentadas em cada momento do dia.

Assim como nas competições de barco a vela, os estudantes estabelecem uma relação de especial relevância com suas casas, ao ponto de as edificações, muitas vezes, desaparecerem como objetos tecnológicos e atuarem como impulsionadoras de uma conscientização mais ampla sobre nossas relações com a natureza. O ambiente criado a partir da reunião de todas as equipes é especialmente propício para esse processo. A essência da tecnologia não é tecnologia, como Heidegger afirma, ao dizer que a essência de algo não é aquele algo (HARVEY, 2008). Devemos cuidar para que a simples implementação de determinadas técnicas não substitua uma necessária mudança em nosso posicionamento perante o meio ambiente, do qual somos parte. Embora dados de monitoramento estejam sempre presentes durante a competição, os estudantes que participam mais ativamente de todo o processo percebem que as casas são uma materialização e um instrumento de algo muito mais amplo, um processo de aprendizagem urgente para a transformação de nossas relações com o ambiente. A performance monitorada não é mais a protagonista. Vemos aqui a questão da sustentabilidade, responsável pela difusão da performance atrelada principalmente ao desempenho, na arquitetura, recuperando outros aspectos do conceito. As casas e seus criadores, nesse evento, são os verdadeiros atores e protagonistas da performance, mais próxima da noção de rito ou do teatro, tendo como objetivo mais importante a educação da sociedade para a ideia de que podemos vislumbrar um futuro sustentável na Terra.

\section{POSSIBILIDADES}

O crescente número de autores e produções que se utilizam do conceito de performance demonstra se tratar de uma temática com grande potencial investigativo. No campo do design computacional verifica-se a predominância da interpretação e aplicação do termo em sua forma mais objetiva e singular, na busca por métodos de projetos mais "precisos" e menos "intuitivos". Percebe-se, nesses termos, a idealização de um fluxo de trabalho que obedece com rigor regras matemáticas e lógicas, visando otimizar a solução projetual, e que remonta às primeiras discussões sobre métodos em projetos da década de 1960. Nesse quadro, o conceito de performance tem se aproximado da ideia de desempenho, da capacidade de um edifício atender determinados critérios, seguindo uma lógica binária, que não abre margem para qualquer tipo de relativização.

Tal abordagem pode provocar alguns questionamentos de ordem cultural e social. O fato, por exemplo, de os critérios avaliativos serem préestabelecidos e não considerarem tempo e apropriação pode nos levar de volta a questões do "antigo funcionalismo". Nesse contexto, a interpretação de performance pode parecer seletiva e simplista.

A aplicação "fechada" do termo também tem contribuído para um tímido diálogo do campo do design computacional com outras áreas do conhecimento, especialmente na esfera artística. O olhar histórico nos 
mostrou que as primeiras considerações sobre performance, quando se percebia o entrelaçamento das teorias performáticas no teatro, nas artes, na música e até em questões de identidade de gênero, potencializavam a pluralidade do termo. Também foi importante verificar, ao resgatar a Virada Performática, as relações de performance com rituais e repetições, visão que é compartilhada por autores até os dias de hoje, quando observam apropriações espaciais e a dinâmica urbana contemporânea. No campo da arquitetura, alguns pontos importantes referentes à performance foram percebidos por meio da análise da obra de autores como Tschumi, com a noção de "acontecimento", Leatherbarrow, com a questão do equilíbrio de forças do corpo edificado e do planejado, e Leach, que levanta a possibilidade de "subverter" o significado de um espaço por meio de seu uso.

Embora, como já mencionado, os experimentos e as práticas envolvendo performance nos últimos anos se aproximem mais da ideia de desempenho, boa parte dos teóricos contemporâneos do campo do design computacional demonstram preocupação em buscar novos horizontes. Nenhum dos autores abordados reduzem a aplicação do termo ao aspecto meramente quantitativo, pelo contrário, procuram meios de estender o entendimento de performance para outros vieses: Hensel considera a organização espacial um fator determinante no processo de design orientado pela performance e busca se apropriar da noção de evento; Oxman propõe a integração de aspectos qualitativos e quantitativos; e Kolarevic sugere a existência de vários tipos de performance, por exemplo, a social, assim como a compreensão de performance enquanto processo.

Um ponto importante, presente na maior parte dos estudos envolvendo performance, é a questão do corpo e do tempo, seja o corpo que "performa" no ambiente criando novas significações espaciais, seja o corpo edificado em constante mutação ou, ainda, o corpo que representa a figura do designer e que no contexto do design computacional emerge de uma relação dinâmica entre autor e obra, por meio de parametrização e sistemas generativos. Nesse viés, os possíveis desdobramentos teóricos de performance baseada em interações de escalas do "corpo" e do espaço parecem ir muito além da dicotomia "otimizado" e "deficitário" recorrente no discurso simplificado sobre performance design.

O morador que ajusta a casa projetada por Glenn Murcutt como se fosse um barco a vela se assemelha aos estudantes das equipes do Solar Decathlon que, por vários dias, promovem diferentes tipos de interação entre o monitoramento da performance em tempo real e a maneira de habitar a casa para que ela aproveite as condições climáticas e ambientais da melhor forma possível. Em ambos os casos, vemos uma aproximação com as casas primitivas, através da conexão com a natureza. Nesse contexto, as casas de Murcutt e do Solar Decathlon surgem como um veículo de "habitar" poeticamente a Terra, conforme sugerido por Heidegger (2002). Em todos os casos, mesmo nas casas primitivas, as técnicas adotadas são decisivas para estabelecer essa relação. Entretanto, seu sucesso está justamente na forma como a essência das soluções tecnológicas faz surgir uma nova relação com a natureza, por meio da arte e da poesia (HARVEY, 2008). O exemplo dos maiores velejadores de regatas, novamente, pode deixar essa relação mais clara. Os barcos a vela cada vez mais são produzidos como um conjunto de soluções tecnológicas de ponta. Entretanto, a perfeição buscada pelos velejadores é alcançada justamente quando o barco deixa de ser importante, e a essência da perfeição procurada é a direta e fenomenológica conexão do velejador com o vento e o mar. Da mesma forma, as soluções tecnológicas reunidas na casa perdem o caráter de objetos a serem manipulados como fim em si mesmos e passam a compor um veículo capaz de liberar o morador da própria edificação para se aprofundar na essência poética do habitar na Terra.

Longe de finalizar o assunto, este artigo buscou levantar algumas questões iniciais relevantes acerca do conteúdo tratado e instigar futuros 
debates. Através das diferentes análises apresentadas conclui-se que é importante para a área de pesquisa do design computacional uma maior reflexão a respeito de seu próprio repertório de palavras, como é o caso do termo performance. Essa investigação semântica pode trazer descobertas e introduzir discussões significativas para o campo de estudo, abrindo caminhos para seu desenvolvimento.

\section{REFERÊNCIAS}

AISH, R.; WOODBURY, R. Multi-level interaction in parametric design. In: BUTZ, A. et al. (Eds.). Smat Graphics 2005. Berlim: Springer, 2005. p. 151-162. Disponível em: <https://goo. gl/94zHUN> Acesso em: 1ำ nov. 2017.

BURRY, J. et al. Design trade-off: sailing as a vehicle for modelling dynamic trade-off design. In: BURRY, J. (Ed.). Designing the dynamic: high-performance sailing and real-time feedback in design. Melbourne: Melbourne Books, 2013. p. 17-23.

BUTLER, J. Gender trouble: feminism and the subversion of identity. London: Routledge, 2006.

CELANI, G. Prefácio à edição brasileira. In: MITCHELL, W. J. A lógica da arquitetura. São Paulo: Unicamp, 2008. p. 5-7.

DREW, P. Leaves of iron: Glenn Murcutt: pioneer of an Australian architectural form. Sydney: Law Book, 1985.

DUARTE, V.G.; NORONHA, M.P.Performance e arquitetura: uma transmutação conceitual a partir do estudo do edifício da Fundação Iberê Camargo, de Álvaro Siza. In: CONGRESSO INTERNACIONAL DO CURSO DE HISTÓRIA DA UFG/JATAII, 2., 2011, Jataí. Anais... Jataí: UFG, 2011. Disponível em: <https://goo.gl/K2MVTx> Acesso em: 1ำ nov. 2017

FERREIRA, A. B. H. Dicionário eletrônico Aurélio século XXI. Rio de Janeiro: Positivo, 2004. 1 CD-ROM, versão 5.0.

HARVEY, S. R. Heidegger and ecophenomenology: Gelassenheit as practice. 2008. 91 f. Dissertação (Mestrado em Artes) - Washington State University, Washington, DC, 2008.

HEIDEGGER, M. Construir, habitar, pensar. In: Ensaios e conferências. Tradução Emmanuel Carneiro Leão, Gilvan Fogel e Marcia Sá Schuback. Petrópolis: Vozes, 2002. p. 125-142.

HENSEL, M. AD primer: performanceoriented architecture: rethinking architectural design and the built environment. London: AD Wiley, 2013. Kindle Edition.

IMAGINE a building that answers the question what does good look like?
International Living Future Institute, Seattle, 17 abr. 2017. Disponivel em: <https:// goo.gl/rFGRGT>. Acesso em: 1ำ nov. 2017.

KOLAREVIC, B.; MALKAWI, A. Performative architecture: beyond instrumentality. New York: Spon, 2010.

LEACH, N. Drag spaces. The London Consortium, London, n. 4, p. 1-7, nov. 2006. Disponível em: <https://goo.gl/Wdaj35>. Acesso em: $1^{\circ}$ nov. 2017

LEATHERBARROW, D. Architecture oriented otherwise. New York: Princetown Architectural, 2009

Prefácio. In: HENSEL, M. AD primer: performance-oriented architecture: rethinking architectural design and the built environment. London: AD Wiley, 2013. Kindle Edition.

LI, C.; HONG, T.; YAN, D. An insight into actual energy use and its drivers in highperformance buildings. Applied Energy, Amsterdam, v. 131, p. 394-410, 2014.

MURCUTT, G. Interview: Glenn Murcutt Talking Heads. Entrevistador: P. Thompson. Sidney: ABC, 2008. Disponível em: <https:// goo.gl/Nch4vb>. Acesso em: 9 nov. 2017.

NEWSHAM, G. R.; MANCINI, S.; BIRT, B. J. Do LEED-certified buildings save energy? Yes, but... Energy and Buildings, Amsterdam, v. 41, n. 8, p. 897-905, 2009.

NOVAK, M. J. Computational composition in architecture. In: ASSOCIATION fOr COMPUTER AIDED DESIGN IN ARCHITECTURE CONFERECENCE, 8., 1988, Michigan. Proceedings... Michigan: Ann Arbor, 1988. p. 5-30. Disponível em: <https:// goo.gl/8tJrb8>

OXMAN, R. Performance-based design: current practices and research issues. International Journal of Architectural Computing, Thousand Oaks, v. 6, n. 1, p. 1-17, 2008. Disponivel em: <https://goo.gl/ ZzuRzz> Acesso em: 20 jun. 2017.

Novel concepts in digital design. In: GU, N.; WANG, X. (Eds.). Computational design methods and technologies: applications in CAD, CAM and CAE education. Hershey: IGI Global, 2012, p. 18-33. 
PÉREZ-GÓMEZ, A. Praise. In: BAEK, J. Architecture as the ethics of climate. London: Routledge, 2016. p. ii.

RODRIGUEZ-UBINAS, E. et al. Passive design strategies and performance of net energy plus houses. Energy and Buildings, Amsterdam, v. 83, p. 10-22, nov. 2014.

SCHECHNER, R. Between theatre and antropology. Philadelphia: University of Pennsylvania Press, 1985.

Performance theory. New York: Routledge, 1988.

TSCHUMI, B. Architecture and disjunction. Cambridge, MA: The MIT Press, 1994.

TWELVE meter yachts and their sailing instruments. Ockan Instruments, Milford,
23 fev. 2013. Disponível em: <https://goo.gl/ kyqAMs> Acesso em: 1ำ nov. 2017.

U. S. DEPARTMENT OF ENERGY. Solar Decathlon. 2017. Disponível em: <https:// goo.gl/yd5kt9>. Acesso em: 1ำ nov. 2017

VARDOULI, T. Sense and sensibility: the behaviourism/phenomenology debate in the Portsmouth Symposium of 1967 on design methods in architecture. Archidoct [S.I.], v. 1, n. 2, p. 82-84, 2014. Disponível em: <https://goo.gl/qTs5Ma>. Acesso em: 1 nov. 2017.

WHAT are polars: everybody talks about them, but what are they? Ockam Instruments, Milford, 3 jun. 2013. Disponível em: <https://goo.gl/gYlsfp>. Acesso em: 1ำ nov. 2017.

\section{Marcio Nisenbaum} marcio.nisen@gmail.com

José Ripper Kós jose.kos@ufsc.br 
